\section{Commentary: Importance of surgical treatment in the era of precision medicine}

\author{
Hiroshi Date, MD
}

In this issue of the Journal, Matsuura and colleagues ${ }^{1}$ reported a single institutional retrospective study on 75 surgically treated patients with lung cancer with ALK rearrangement. Using propensity score matching, another 75 patients with ALK non-rearrangement were identified and compared. The ALK rearrangement group showed better survival, greater incidence of oligometastasis, and better survival after recurrence with ALK-TKI and/or local ablative therapy (LAT). The authors concluded that a combination of local and systemic therapies is an important treatment strategy for ALK-rearranged lung adenocarcinoma. They are to be congratulated for completing this important study.

ALK-rearranged non-small cell lung cancer (NSCLC) accounts for $3 \%$ to $5 \%$ of all NSCLC cases. The striking benefit of ALK-tyrosine kinase inhibitors has been reported for patients with advanced disease and have drawn favorable attention. ${ }^{2}$ However, the effect of surgical treatment has not been much investigated. This study appears to be the largest experience of surgical treatment for NSCLC with such a mutation.

Among the 75 patients with ALK-rearrangement, 53 patients $(70.7 \%)$ did not develop recurrence, and they appeared be cured only by surgical treatment. This finding is very important to confirm that surgical removal of lung cancer is the most reliable treatment for local disease.

Another important issue was oligometastasis. Greater incidence of oligometastasis in the ALK-rearranged group and the possible benefit of LAT were suggested. Although it was not clear whether LAT was specifically beneficial

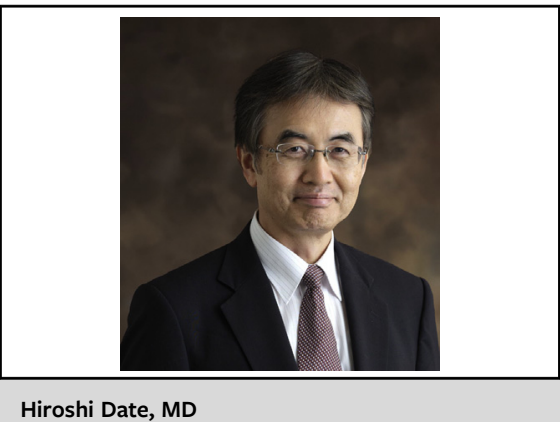

Hiroshi Date, MD

CENTRAL MESSAGE

Surgically treated patients with

lung cancer with ALK rearrange-

ment showed better survival, greater incidence of oligometastasis, and better survival after recurrence.

for patients with this subset, excellent postrecurrence survival reported was encouraging.

The development of specific inhibitors targeting driver mutations and immunotherapy have played an important role in the treatment for NSCLC. However, the most important message of the current issue, the importance of surgical treatment in the era of precision medicine, needs to be kept in mind.

\section{References}

1. Matsuura Y, Ninomiya H, Ichinose J, Nakao M, Okumura S, Nishio M, et al. Prognostic impact and distinctive characteristics of surgically resected anaplastic lymphoma kinase-rearranged lung adenocarcinoma. J Thorac Cardiovasc Surg. 2022; 163:441-51.e1.

2. Solomon BJ, Mok T, Kim DW, Wu YL, Nakagawa K, Mekhail T, et al. First-line crizotinib versus chemotherapy in ALK-positive lung cancer. $N$ Engl J Med. 2014; $371: 2167-77$.

\footnotetext{
From the Department of Thoracic Surgery, Graduate School of Medicine, Kyoto University, Kyoto, Japan.

Disclosures: The author reported no conflicts of interest.

The Journal policy requires editors and reviewers to disclose conflicts of interest and to decline handling or reviewing manuscripts for which they may have a conflict of interest. The editors and reviewers of this article have no conflicts of interest.

Received for publication Nov 1, 2020; revisions received Nov 1, 2020; accepted for publication Nov 2, 2020; available ahead of print Nov 6, 2020.

Address for reprints: Hiroshi Date, MD, Department of Thoracic Surgery, Graduate School of Medicine, Kyoto University, 54 Kawahara-cho, Shogoin, Sakyo-ku, Kyoto 606-8507, Japan (E-mail: hdate@kuhp.kyoto-u.ac.jp).

J Thorac Cardiovasc Surg 2022;163:455

$0022-5223 / \$ 36.00$

Copyright (C) 2020 by The American Association for Thoracic Surgery

https://doi.org/10.1016/j.jtcvs.2020.11.006
} 